\title{
Antioxidant Capacity and Phenolic Antioxidants of Midwestern Black Raspberries Grown for Direct Markets Are Influenced by Production Site
}

\author{
Mustafa Ozgen ${ }^{1}$ \\ Department of Horticulture, Gaziosmanpaşa University, Tasliciftlik, Tokat, \\ Turkey 60240
}

Faith J. Wyzgoski

Department of Chemistry, The Ohio State University at Mansfield, 1760

University Drive, Mansfield, OH 44906

Artemio Z. Tulio, Jr. ${ }^{3}$, Aparna Gazula ${ }^{4}$, A. Raymond Miller ${ }^{5}$, and

Joseph C. Scheerens ${ }^{2,7}$

Department of Horticulture and Crop Science, The Ohio State University, Ohio Agricultural Research and Development Center, 1680 Madison Avenue, Wooster, OH 44691

\section{R. Neil Reese ${ }^{5}$}

Department of Biology and Microbiology, NPB 249B, Box 2140D, South Dakota State University, Brookings, SD 57007

\section{Shawn R. Wright ${ }^{6}$ \\ The Ohio State University South Centers, 1864 Shyville Road, Piketon, $\mathrm{OH}$ 45661}

Additional index words. Rubus occidentalis, phytonutrient, anthocyanin, DPPH, FRAP, environmental variation

\begin{abstract}
Black raspberries (Rubus occidentalis L.) are rich in phytonutrients that have demonstrated chemoprotective properties against certain degenerative diseases. To estimate variability in phytonutritional quality among sources of black raspberry, 19 samples representing four common midwestern cultivars obtained from eight production sites were assayed for their antioxidant capacity [2,2-diphenyl-1-picrylhydrazyl (DPPH) and ferric reducing ability of plasma (FRAP) methods], total phenolic content (TP), total monomeric anthocyanin levels (TMA), and levels of cyanidin 3-rutinoside. The antioxidant potential among samples averaged $2.92 \pm 0.29$ and $4.62 \pm 0.88 \mathrm{mmol} \mathrm{TE} \cdot 100 \mathrm{~g}^{-1}$ fresh weight by the DPPH and FRAP methods, respectively; TP, TMA, and cyanidin 3-rutinoside means averaged $449 \pm 62,336 \pm 109$, and $244 \pm 84 \mathrm{mg} \cdot 100 \mathrm{~g}^{-1}$ fresh weight, respectively. Levels of FRAP, TP, TMA, and cyanidin 3-rutinoside were strongly correlated $(r=+0.85$ to +0.96$)$. Mean antioxidant capacities and phenolic constituent levels were similar among 'Bristol', 'Jewel', and 'MacBlack' samples; values for a single sample of 'Haut' were lower but comparable to levels found in individual samples of the other three cultivars. Black raspberry production site differences were statistically significant for FRAP, TMA, cyanidin 3-rutinoside, and titratable acidity (TA) levels. Inverse relationships $(r=-\mathbf{0 . 6 5}$ to $-\mathbf{0 . 7 4})$ among black raspberry samples for FRAP, TMA, or cyanidin 3-rutinoside levels versus levels of TA suggested that site differences may be partially attributable to fruit ripeness at harvest. Relationships among these parameters versus regional differences in soil temperatures were also significant but weak. Regardless of its environmental or physiological drivers, point-source variation in fruit phytonutrient contents may be a relevant concern in health-related studies or clinical applications. Moreover, it may impact the nutritional benefits to the consumer and affect the quality advantages associated with direct-marketed black raspberries.
\end{abstract}

Naturally occurring antioxidants in fruits and vegetables impart potential health benefits, specifically for limiting the onset and/or severity of several degenerative diseases of aging. The prospective benefits of antioxidant-rich produce has led governmental and private agencies worldwide to promote increased consumption of these commodities to improve personal health and decrease societal healthcare costs (U.S. Department of Health and Human Services, U.S. Department of Agriculture, 2005; World Health Organization, 2003). In response, consumer demand for fresh, locally produced fruit of high quality and nutritional value has grown, fostering the adoption of value-added direct marketing approaches by midwest producers (Ellerman and McFeeters, 2001).

Among commonly consumed produce, fruits of Rubus spp. are known to have strong antioxidant capacity mainly as a result of high levels of anthocyanins and other phenolic compounds (Wu et al., 2004). However, phenolic compound levels and antioxidant capacities associated with these fruits differ widely among species (Benvenuti et al., 2004; Moyer et al., 2002; Wang and Lin, 2000). Within species, they can be influenced by genetics (Connor et al., 2005a, 2005b, 2005c, 2005d; McGhie et al., 2002), production site (Anttonen and Karjalainen, 2005; Connor et al., 2005a), year of production (Anttonen and Karjalainen, 2005), ripening stages (Ozgen et al., 2006a; Wang and Lin, 2000), postharvest conditions (Kalt et al., 1999), and processing (Zafrilla et al., 2001).

Within Rubus, black raspberries (Rubus occidentalis L.) have been extensively examined as potential chemopreventive agents for various forms of aerodigestive cancers (Stoner et al., 2007). Early studies focused on the phenolic compound, ellagic acid, as a primary bioactive compound (Maas et al., 1991). However, Xue and coworkers (2001) demonstrated that, in addition to ellagic acid, a methanolic extract of black raspberries prevented the carcinogenic transformation of Syrian hamster embryo cells challenged with benzo $[a]$ pyrene, a potent carcinogen. Later, Han and coworkers (2005) found $\beta$-sitosterol, ferulic acid, and unknown compounds in a black raspberry ethanolic extract to normalize cell cycling and/or curtail cell proliferation in premalignant and malignant human oral cell lines. Detailed highperformance liquid chromatography (HPLC) subfractionation of black raspberry ethanol and water extracts indicated cyanidin 3-glucoside, cyanidin 3-xylosylrutinoside, and cyanidin 3-rutinoside to be major constituents of the most chemopreventive subfractions in a mouse epidermal cell bioassay (Hecht et al., 2006). Based on their potency as antioxidants and their concentration in extracts, the latter two compounds accounted for a substantial portion of the phenolic antioxidant activity among black raspberry field samples (Tulio et al., 2008). Studies by Stoner et al. (2005) and Tian et al. (2006) demonstrated the ellagic acid and anthocyanins to be bioavailable in black raspberrybased clinical treatments and the treatments to be well tolerated by human subjects. Clinical trials examining the chemopreventive effects of black raspberry on several aerodigestive cancers are underway with a study of patients with Barrett's esophagus treated with freeze-dried black raspberry suspensions being the closest to completion (Kresty et al., 2006).

Like with other Rubus, black raspberry phytonutrient levels may be affected by genetic, cultural, and/or environmental factors. Black raspberry producers wishing to 
optimize antioxidant levels of their fruit products must consider how greatly antioxidant levels might vary among locally grown cultivars from harvest site to harvest site and as a consequence of how they are handled and marketed. An accurate assessment of phytonutrient variability among locally grown products might also reflect potential nutritional differences a consumer might expect when acquiring black raspberries from different sources. Moreover, genetic or environmental variability in black raspberry's potential bioactive components would have important implications for the reproducible formulation of specific clinical products for medical studies or treatment regimens. In this study, we ascertained the phenotypic variation among and within black raspberry cultivars commonly direct-marketed in the midwest. The goals of our study were as follows: 1) to measure the antioxidant capacity and to quantify total phenolic and anthocyanin constituents of some well-known midwest black raspberry cultivars; and 2) to investigate the variability among samples within cultivars associated with growing sites. Our objectives were similar to previous studies reporting black raspberry values (e.g., Moyer et al., 2002), but our focus was to ascertain more closely the antioxidant benefits that one might expect by purchasing black raspberries "on-farm" or in local markets.

\section{Materials and Methods}

Plant materials and production sites. Nineteen commercially ripe black raspberry fruit samples were harvested by producers from healthy plants grown at eight Ohio production sites. Samples were frozen within $24 \mathrm{~h}$ of harvest in on-farm, conventional freezers. These materials were transported in their frozen state to the Ohio Agricultural Research and Development Center (OARDC) and then stored in 100-g batches at $-29{ }^{\circ} \mathrm{C}$ until analyzed. An inventory of site and soil characteristics, planting condition and cultural practices, and yield characteristics at each site was compiled from information supplied by producers. Regional climatic differences were estimated from 2004 OARDC Weather System data (OARDC, 2007) collected at the four stations [the Northwest Station (lat. $41.28^{\circ} \mathrm{N}$, long. $83.84^{\circ} \mathrm{W}$, elevation $693 \mathrm{~m}$ ), the Piketon Station (lat. $39.07^{\circ} \mathrm{N}$, long. $83.01^{\circ} \mathrm{W}$, elevation $578 \mathrm{~m}$ ), the Western Station (lat. $39.83^{\circ}$
$\mathrm{N}$, long. $83.63^{\circ} \mathrm{W}$, elevation $1124 \mathrm{~m}$ ), and the Wooster Station (lat. $40.77^{\circ} \mathrm{N}$, long. $81.93^{\circ}$ $\mathrm{W}$, elevation $311 \mathrm{~m})$ ] closest to the sites. Climatic data means for each were compiled with reference to the fruiting period of each sample (i.e., $7 \mathrm{~d}$ before to $10 \mathrm{~d}$ after typical harvest initiation date) at each site within the region.

Analytical procedures. For each fruit sample, three replicates were thawed at room temperature and then homogenized in a standard food blender; for each replicate, excess fruit (100-g lots) were used to minimize possible naturally occurring fruit to fruit variation. Slurries were assayed for soluble solid contents by refractometry and for levels of titratable acidity (TA) using the methodology of Perkins-Veazie et al. (1996).

A single extraction procedure designed to assay phenols (Singleton and Rossi, 1965) was used to determine total soluble phenolic content (TP), total monomeric anthocyanin levels (TMA), and antioxidant capacity of all samples. For each replicate, a 3-g aliquot of slurry was transferred to polypropylene tubes and extracted with $40 \mathrm{~mL}$ of extraction buffer containing acetone, water, and acetic acid (70:29.5:0.5 by volume) for $1 \mathrm{~h}$. After filtration, acetone was removed by rotary evaporation and then the concentrated samples were brought to a final volume of $40 \mathrm{~mL}$ with distilled, deionized water. All laboratory procedures were performed in duplicate for each replicate extraction.

The total antioxidant capacity of each sample was estimated by two standard procedures, the ferric reducing ability of plasma (FRAP) assay and the 2,2-diphenyl-1-picrylhydrazyl (DPPH) procedure as described by Ozgen et al. (2006b). For each replicate, TP levels were determined colorimetrically after reaction with Folin-Ciocalteu's phenol reagent following the method described by Singleton et al. (1999). Values of TP were estimated by comparing the absorbance of each duplicate with those of a response curve generated in triplicate with a commercial standard of gallic acid (Sigma/Aldrich, St. Louis, MO). Response curves were also prepared using catechin and quercetin (Sigma/ Aldrich), cyanidin 3-glucoside (kuromanin chloride; Chromadex, Santa Ana, CA), and cyanidin 3-rutinoside (Polyphenols Laboratories AS, Sandnes, Norway) for comparison. The TMA content of each sample was measured with a $\mathrm{pH}$ differential method de- scribed by Giusti and Wrolstad (2005). Anthocyanin content of each duplicate was calculated using the molar absorptivity $(\varepsilon)$ and molecular weight (MW) of cyanidin 3 -rutinoside $(\varepsilon=30,185$; $\mathrm{MW}=631.0)$ as described by Tulio et al. (2008).

Individual anthocyanins were also characterized by HPLC using a SpectraSystem P4000 liquid chromatograph equipped with binary pumps (Spectra-Physics Analytical, Inc., San Jose, CA) and an ultraviolet-visible detector (SpectraSystem Model \#UV1000) interfaced to an IBM computer with PC1000 System software (Thermo Separation Products, San Jose, CA). Separation was carried out on a Lichrosorb reversed-phase C18 column, $250 \times 4.6 \mathrm{~mm}$ i.d., $5 \mu \mathrm{m}$ (Alltech Associates, Inc., Deerfield, IL) fitted with an Adsorbosphere $\mathrm{C} 18$ guard column $(7.5 \times 4.6$ $\mathrm{mm}$ i.d., $5 \mu \mathrm{m}$; Alltech Associates, Inc.) following the procedure of Tian et al. (2005) with modifications. The mobile phase consisted of acidified water ( $1 \%$ formic acid) as solvent $\mathrm{A}$ and acidified acetonitrile (1\% formic acid) as solvent $B$; the portion of solvent $B$ in the solvent mixture was increased in a linear gradient from $10 \%$ to $50 \%$ in $15 \mathrm{~min}$, then decreased in a linear gradient from $50 \%$ to $10 \%$ in $5 \mathrm{~min}$, and then held isocratically at $10 \%$ of the mixture for an additional $5 \mathrm{~min}$ to re-equilibrate the column. The flow rate was 1 $\mathrm{mL} \cdot \mathrm{min}^{-1}$ and the injection volume was 20 $\mu \mathrm{L}$. The detection wavelength was $520 \mathrm{~nm}$. Solvents were filtered through a Millipore filter type HA (Millipore Corp., Bedford, MA).

The cyanidin 3-rutinoside peak within black raspberry chromatograms was initially identified and quantified using the commercial standard described previously. After repeated collection and concentration of the HPLC column eluate under $\mathrm{N}_{2}$, the identity and purity of this peak was confirmed by high-field ${ }^{1} \mathrm{H}$ NMR with a Varian INOVA 750-MHz NMR spectrometer (Varian Inc., Palo Alto, CA) using a Varian triple resonance ${ }^{1} \mathrm{H}\left\{{ }^{13} \mathrm{C} /{ }^{15} \mathrm{~N}\right\}$ pulsed-field gradient cryoprobe. Solid material derived from the column eluate was redissolved in $250 \mu \mathrm{L}$ of a solution containing methanol- $\mathrm{d}_{4}$ and trifluoroacetic acid-d (95:5 by volume) and tetramethylsilane as an internal reference standard. Sample solutions were transferred to NMR tubes with a $5-\mathrm{mm}$ diameter that tapered to $2.5 \mathrm{~mm}$ in the active region of the coil. The spectra were collected at $25^{\circ} \mathrm{C}$ over

\footnotetext{
Received for publication 11 Feb. 2008. Accepted for publication 24 Apr. 2008.

Manuscript No. HCS08-13. Salaries and research support provided in part by State and Federal Funds appropriated to the Ohio Agricultural Research and Development Center, The Ohio State University. This work was also supported by a U.S. Department of Agriculture Special Grant for Dietary Intervention 2003-34501-13965.

Use of trade names does not imply endorsement of the products named or criticism of similar products not named.

We thank Peter L. Rinaldi, Ruiling Fu, and members the University of Akron, Department of Chemistry's Molecular Spectroscopy Laboratory for use of their NMR facility and for their expertise and assistance. We also thank the fruit producers of Ohio that contributed fruit accessions and their time to ensure the completion of this work.

${ }^{1}$ Assistant Professor.

${ }^{2}$ Associate Professor.

${ }^{3}$ Postdoctoral Researcher. Current address: Horticultural Sciences Department, University of Florida, P.O. Box 110690, Gainesville, FL 32611-0690.

${ }^{4}$ Former Research Aide. Current address: Horticultural Sciences Department, University of Florida, P.O. Box 110690, Gainesville, FL 32611-0690.

${ }^{5}$ Professor.

${ }^{6}$ Adjunct Assistant Professor.

${ }^{7}$ To whom reprint requests should be addressed; e-mail scheerens.1@osu.edu
} 
a spectral width of $8.5 \mathrm{k}$ with a $6.6-\mu \mathrm{s}\left(90^{\circ}\right)$ pulse. The acquisition time was $2.0 \mathrm{~s}$ and 128 transients were accumulated with a 5-s delay. Data were processed with a $0.5 \mathrm{~Hz}$ exponential line broadening and zero filled to $128 \mathrm{k}$ points before Fourier transformation. Confirmation of the chromatographic material as containing a single anthocyanin, cyanidin 3-rutinoside was based on comparison with the ${ }^{1} \mathrm{H}-\mathrm{NMR}$ spectra of standard materials. Distinctive resonances for cyanidin 3-rutinoside used to confirm compound identity were a singlet at $8.958 \mathrm{ppm}$ for $\mathrm{H} 4$ of the aglycone and a doublet centered at $1.164 \mathrm{ppm}$ (J, 6.241 $\mathrm{Hz}$ ) indicating the presence of the protons from the methyl group on the rhamnosyl portion of the rutinoside structure. The lack of additional resonances associated with other anthocyanins was considered for assigning an eluate purity of $100 \%$ (within assay tolerances).

Data analysis. Laboratory duplicates were averaged in all cases. Variability among and within species and relationships among variables were examined using SAS software (SAS Institute, Cary, NC) and procedures (i.e., PROC GLM, PROC MEANS, PROC CORR). Species and cultivar values are reported as means \pm SDS of the mean, whereas values for individual samples are reported as means \pm SES of the mean.

\section{Results and Discussion}

Phytonutrient levels and relationships among parameters. The antioxidant potential among black raspberry samples in our study averaged $2.92 \pm 0.29$ and $4.62 \pm 0.88$ mmol TE $100 \mathrm{~g}^{-1}$ on a fresh weight basis as determined by the DPPH and FRAP methods, respectively. The antioxidant capacity estimates we obtained were similar to those reported in our previous study for raw black raspberry juice (Ozgen et al., 2006b), but less than the average FRAP values obtained from whole fruit of three cultivars in a study by Moyer et al. (2002). Moyer and his coworkers accredited the high values they obtained in part to their exacting extraction procedures, which included cryogenic milling for strict control of oxidative enzymatic activity during sample processing. In addition to improved phenolic extraction and recovery, their milling technique may have resulted in milled samples containing portions of antioxidant-rich but predominantly indigestible seed tissue, according to these authors. Black raspberry antioxidant capacity was estimated in several studies (e.g., Moyer et al., 2002; Wang and Lin, 2000; Wang and Zheng, 2005) using the oxygen radical absorbance capacity procedure, but differences in antioxidant assays render direct comparisons with our data impractical (Ozgen et al., 2006b).

In general, berry crops exhibit elevated antioxidant capacities and are effective scavengers of several reactive oxygen species primarily as a result of the high levels of phenolic acids, flavonoids, and other polyphenolic compounds found in their ripe fruits (Wang and Lin, 2000). In this study, we determined TP and TMA means to be $449 \pm$ 62 and $336 \pm 109 \mathrm{mg} \cdot 100 \mathrm{~g}^{-1}$ on a fresh weight basis, respectively. The TMA values spectrophotometrically estimated here for the 19 samples agreed well with estimates of their anthocyanin concentrations $(311 \pm 105$ $\mathrm{mg} \cdot 100 \mathrm{~g}^{-1}$ fresh weight) as determined chromatographically with HPLC peaks quantified using anthocyanin standards (data not shown). Our mean value of TMA was midrange among values for a population of black raspberry breeding stock (McGhie et al., 2002) and agreed closely with those found by Wang and Lin (2000) and Wang and Zheng (2005) using similar techniques. However, our values for both parameters were less than those reported by authors using extensive sample milling and/or extraction protocols (e.g., Moyer et al., 2002).

Anthocyanins have been shown to be the predominant phenolic antioxidants in this dark-fruited species (Tulio et al., 2008) and they are apparently in greatest proportion among the black raspberry flavonoids (Seeram et al., 2006; Wang and Zheng, 2005). In this study, TMA estimates averaged $73 \%$ of their corresponding TP values, but comparisons for individuals ranged from $37 \%$ to $104 \%$. However, such direct assessments of the contribution of TMA to TP levels can be problematic because the parameters are estimated from absorbance values by different mathematical conversions. In this study, calculations of TMA were based on the molar absorptivity coefficient and molecular weight of cyanidin 3-rutinoside, the predominant anthocyanin moiety, although samples from different sources have been shown to vary in the relative concentration of individual anthocyanins within their profiles (Tulio et al., 2008). Complexity and variability within the anthocyanin profile can result in over- or underestimated TMA levels (Benvenuti et al., 2004). Moreover, individual phenolics react with Folin-Ciocalteu reagent with varying strength as a result of differences in chemical structure and the number and reactivity of phenolic hydroxyl groups (Singleton et al., 1999). Because standard curves are typically expressed in weight equivalents rather than molarity, large differences in formula weight between the standard used and the predominant phenolic compound present in samples (e.g., MWs 170 and $631 \mathrm{~g} \cdot \mathrm{mol}^{-1}$ for gallic acid and cyanidin 3 -rutinoside, respectively) may also profoundly affect spectrophotometric estimates for TP. A comparison of Folin-Ciocalteu standard curves for cyanidin 3-rutinoside, cyanidin 3-glucoside, catechin, gallic acid, and quercetin exemplified these differences (Fig. 1). In comparison with others, the regression equation generated by gallic acid may have underestimated our phenolic values, especially in the most anthocyanin-rich samples.

Because phenolic antioxidants predominate in Rubus fruit, strong relationships among measures of total phenolic content, anthocyanin levels, and antioxidant capacity are often reported (e.g., Connor et al., 2005a, 2005d; Moyer et al., 2002; Wang and Lin, 2000). From our data, we calculated very strong phenotypic correlation coefficients $(r)$ between the TP values of black raspberry samples and their respective antioxidant capacities as determined by the FRAP assay (Table 1). The strong relationship evident between black raspberry TMA and FRAP values supported the work of Tulio et al. (2008) establishing anthocyanins, and specifically cyanidin 3 -rutinoside and cyanidin 3-xylosylrutinoside, as primary phenolic antioxidants in this species. Moreover, the strong correlation between TP and TMA values further substantiated the predominance of anthocyanin constituents among the black raspberry phenolic pool. Moyer et al. (2002) also reported a strong correlation $(r=0.83)$ between these parameters among 37 diverse but predominantly blackberry (Rubus spp. L.) and blackberry hybrid samples.

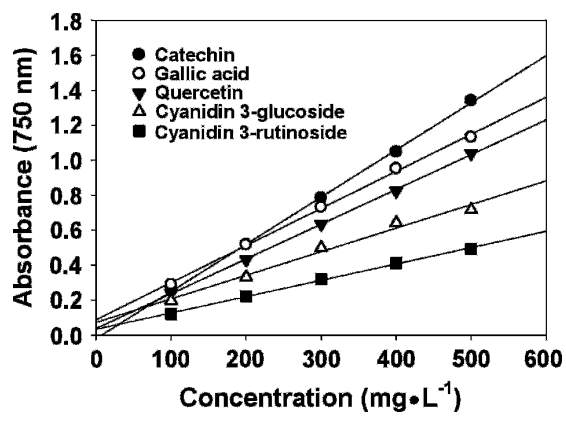

Fig. 1. Variable response of phenolic standards to Folin-Ciocalteu reagent.

Table 1. Correlative relationships among antioxidant potentials, total phenolic contents, and total monomeric anthocyanin levels of 19 samples of 'Bristol', 'Haut', 'Jewel', or 'MacBlack' black raspberries grown at six Ohio production sites ${ }^{\mathrm{z}}$.

\begin{tabular}{|c|c|c|c|}
\hline & Antioxidant potential & Total phenolic & Total monomeric \\
\hline Characteristics $^{\mathrm{y}}$ & $\overline{\mathrm{DPPH}}$ & content & anthocyanin level \\
\hline
\end{tabular}

DPPH

FRAP

Total phenolic

content

Total monomeric

anthocyanin conten

Cyanidin 3-rutinoside

$+0.50 * \quad+0.85 * *$

$+0.96 * *$
$+0.85 * *$

${ }^{z}$ Values in table represent statistically significant correlation coefficients from analysis of replicate values. ${ }^{y}$ Characteristics: DPPH and FRAP are acronyms for total antioxidant capacity as determined by the ferric reducing ability of plasma and the 2,2-diphenyl-1-picrylhydrazyl procedures, respectively.

Ns,*,*** Nonsignificant and significant at $P \leq 0.05$ and 0.0001 respectively. 
Variability among black raspberry samples Antioxidant capacity, TP and TMA levels, and levels of cyanidin 3-rutinoside associated with five 'Bristol', one 'Haut', seven 'Jewel', and six 'MacBlack' black raspberry samples is presented in Figure. 2A-E. Cultivar means and SDS are presented along with means and SEs for individual samples. Mean antioxidant capacities among 'Bris- tol', 'Jewel', and 'MacBlack' samples were similar (Fig. 2A-B); antioxidant capacity values for the single sample of 'Haut' were lower than the means of other cultivars but were comparable to individual samples of each.

However, the antioxidant capacities and phenolic constituent levels among samples within cultivars obtained from different production sites varied substantially (Fig. 2A-
E). Variability among samples from different sites was greater for TMA estimates than for estimates of TP, FRAP, or DPPH [coefficients of variability $(\mathrm{CVs})=32 \%, 14 \%, 19 \%$, and $10 \%$, respectively]. Because FRAP, TP, and TMA were highly correlated (Table 1), the pattern of sample variability among and within cultivars was similar for estimates of the three parameters (Fig. 2B-D). The TMA
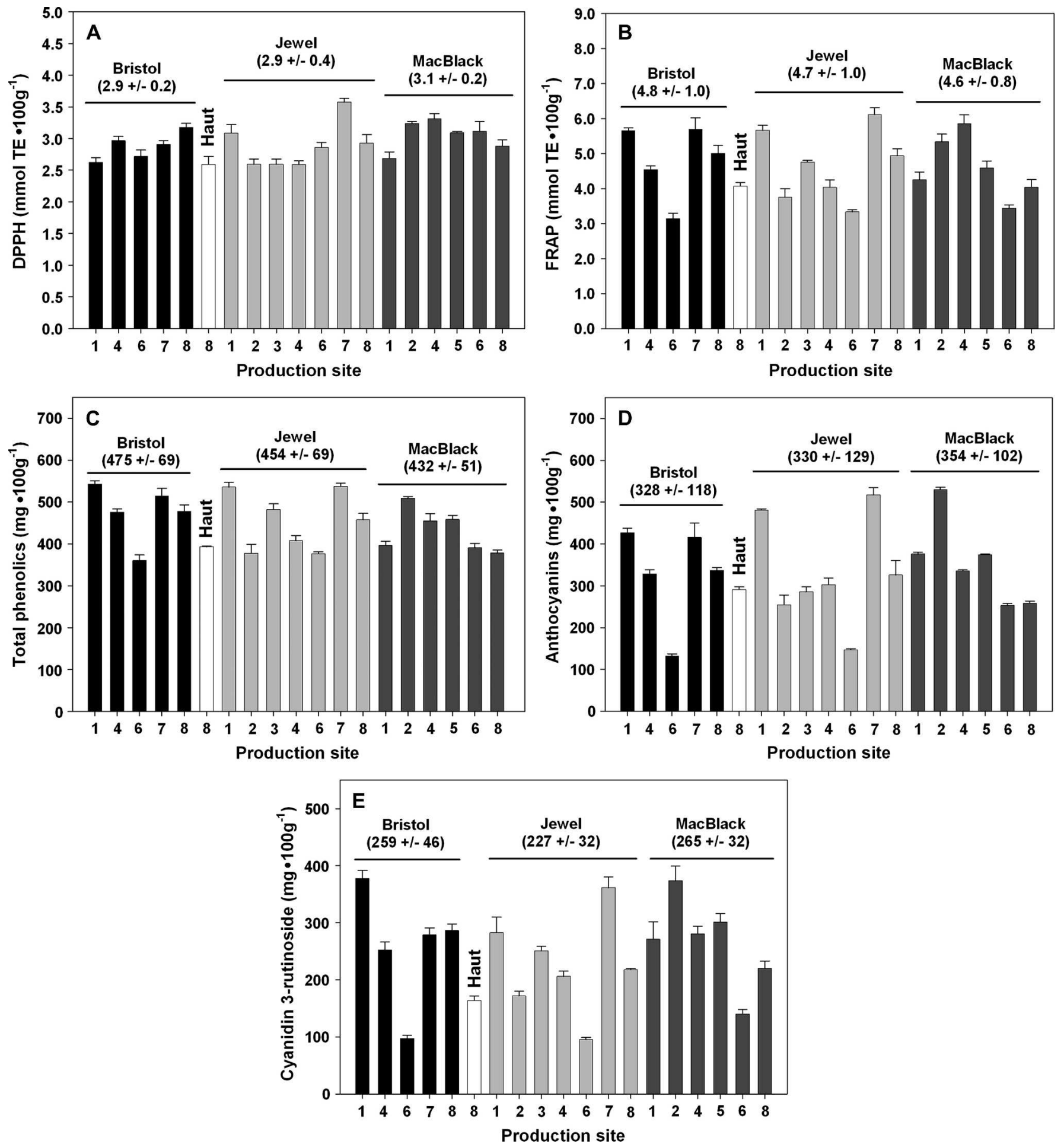

Fig. 2. Antioxidant potential, phenolic and monomeric anthocyanin levels, and levels of cyanidin 3-rutinoside among 19 samples of black raspberry obtained from eight production sites in Ohio. Means and ses of the means for 'Bristol', 'Haut', 'Jewel', and 'MacBlack' samples are represented by black, white, light gray, and dark gray bars, respectively. Cultivar means and sDs of the means for 'Bristol', 'Jewel', and 'MacBlack' are displayed above the bars. The data are expressed on a fresh weight basis. (A) Antioxidant capacity as measured by the 2,2-diphenyl-1-picrylhydrazyl assay; (B) antioxidant capacity as measured by the ferric reducing ability of plasma assay; (C) total phenolic content; (D) total monomeric anthocyanin content; (E) levels of cyanidin 3-rutinoside. 
values ranged within the spectrophotometric or chromatographic estimates of black raspberry anthocyanin contents reported by McGhie et al. (2002), Moyer et al. (2002), and by Wang and Lin (2000). Levels of cyanidin 3-rutinoside, a predominant anthocyanin and antioxidant of black raspberry (Tulio et al., 2008), fluctuated among samples in a manner similar to, but distinct from, that of TMA (Fig. 2D-E; Table 1).

The phytonutrient content of 'Bristol', 'Jewel', and 'MacBlack' were not statistically different, but analysis of variance uncovered statistical differences among six production sites for FRAP, TMA, cyanidin 3-rutinoside, and TA levels (Table 2). Significant relationships between sample TA levels versus FRAP and TMA values and, to a lesser extent, with cyanidin 3-rutinoside values (Fig. 3) suggested that differences in berry phytonutrient profiles among production sites may have been attributable in part to berry ripeness as affected by harvest timing. Significant changes in TMA levels and, to a lesser extent, those of TP and antioxidant capacity during the ripening process have been reported in black raspberry and in other Rubus fruit (Ozgen et al., 2006a; Wang and Lin, 2000). However, in a subsequent 2006 study (data not shown), samples of fully ripe fruit harvested from the same production sites by members of our research team displayed similar patterns of variability for TP, TMA, and FRAP levels. For instance, 'Jewel' harvested from Site 7 was ranked first or second among samples for all three parameters in both years. Moreover, correlation analyses of 2004 versus 2006 sample means yielded significant coefficients for TP levels $(r=0.71)$ and FRAP values $(r=0.68)$, whereas TA levels among these two data arrays appeared to be unrelated $(r=-0.25)$.

The similarity in antioxidant capacity and in antioxidant-active phenolic compounds among black raspberry cultivars may reflect the close familial relationship between 'Jewel' and 'Bristol' ('Jewel's' maternal parent) and the general lack of genetic diversity among common cultivars within the species (Weber, 2003). Conversely, sub- stantial phenotypic diversity in antioxidant capacity and phenolic compounds among cultivars and breeding stock in black raspberry and other Rubus species has been reported routinely (e.g., Anttonen and Karjalainen, 2005; Benvenuti et al., 2004; Connor et al., 2005a, 2005b, 2005c, 2005d; Mazza and Miniati, 1993; McGhie et al., 2002; Moyer et al., 2002). Mazza and Miniati (1993) cited evidence suggesting red raspberry anthocyanin synthesis to be environmentally influenced, but to be predominantly under the genetic control of a few genes, with anthocyanin profiles being a relatively distinct character of each cultivar. In red raspberry breeding studies, Connor et al. (2005c, 2005d) uncovered significant genetic effects for FRAP activity, TP levels, and HPLCdetermined anthocyanin contents and estimated narrow sense heritabilities $\left(h^{2}\right)$ for these traits at $0.54,0.48$, and 0.74 , respectively. This research group also reported significant genetic effects associated with values of FRAP, TP, and anthocyanin among blackberry and blackberry-interspecific hybrid cultivars (Connor et al., 2005a, 2005b). However, in these studies, variance components indicated from $39 \%$ to $55 \%$ of the total variability among samples to be attributable to cultivar $\times$ environment (year and/or site) interactions. Similarly, Anttonen and Karjalainen (2005) demonstrated substantial differences in the content of nonanthocyanin phenolic compounds among commercially produced yellow and red raspberry cultivars, but also found significant effects of production site and year associated with levels of quercetin, a common plant flavonoid.

Soil conditions, nutrient availability, salinity, water availability, and plant health may contribute to production site or production year differences in antioxidant-active compounds of fruits and vegetables (Kalt, 2005). However in our study, production sites and the cultural practices that were used were similar in many respects according to grower-supplied information. The topography of sites was reported to be flat or gently rolling. Row orientation was north to south at all sites, except Site 5. All sites except Site 2 used a fertility monitoring program and only one site (Site 1) reported nutritional challenges (high iron levels). Pest challenges were described as minimal, predominantly orange rust (Arthuriomyces peckianus) and rednecked or raspberry cane borers (Agrilus ruficollis F. and Oberea bimaculata Oliver, respectively), which were managed by appropriate commercial practices. All sites were equipped with either drip and/or overhead irrigation systems. Irrigation was scheduled in accordance with local rainfall patterns and the experienced producers' intuitive knowledge of day-to-day crop condition and needs. Irrigation water availability was not a limiting factor in 2004. Admittedly, fruit fresh weight phytonutrient contents may have been influenced by differences in fruit dry weight if plant water status varied among production sites at or before harvest. Fruit dry weights were not determined for samples in this study, but dry weight percentages among fruit samples harvested from the same production sites in 2006 were relatively consistent $(\mathrm{CV}=4.8 \%)$, far below the phytonutrient variability levels we report here.

Production site characteristics that differed are presented in Table 3. Not all sites had ideal soil conditions. According to Ohio recommendations (Funt et al., 1999), brambles prefer well-drained, sandy loam to loam soils that are high in organic matter and slightly acidic (pH 5.8 to 6.8 ). Growers producing black raspberries on heavier soils compensated for these conditions in part by producing black raspberries on raised beds. Most plantings were from 3 to 5 years old; older plantings, most notably the 22-year-old stand of 'Bristol' at Site 1, produced acceptable yields of phenolic-rich fruit (Fig. 2C-E). Canopy density ratings as estimates of fruit shading during development were highly variable from site to site.

The location, year, or cultural effects on antioxidant-active compounds of fruits and vegetables may be mediated by variability in light levels and ambient temperature (Kalt, 2005). Among small fruits, environmental influences on phytonutrient content and

Table 2. Antioxidant potential, phenolic and monomeric anthocyanin levels, and soluble solid and titratable acidity levels of 'Bristol', 'Jewel', or 'MacBlack' black raspberries grown at six Ohio production sites ${ }^{z}$.

\begin{tabular}{|c|c|c|c|c|c|c|c|c|}
\hline \multirow{2}{*}{$\begin{array}{l}\text { Production site } \\
\text { designation and } \\
\text { relative location }\end{array}$} & \multirow[b]{2}{*}{$\mathrm{N}^{\mathrm{x}}$} & \multicolumn{2}{|c|}{ Antioxidant potential $^{\mathrm{w}}$} & \multirow{2}{*}{$\begin{array}{c}\text { Total } \\
\text { phenolic } \\
\text { content }(\mathrm{mg} / 100 \mathrm{~g})\end{array}$} & \multirow{2}{*}{$\begin{array}{l}\text { Total monomeric } \\
\text { anthocyanin level } \\
(\mathrm{mg} / 100 \mathrm{~g})\end{array}$} & \multirow{2}{*}{$\begin{array}{l}\text { Cyanidin } \\
\text { 3-rutinoside level } \\
(\mathrm{mg} / 100 \mathrm{~g})\end{array}$} & \multirow{2}{*}{$\begin{array}{l}\text { Soluble } \\
\text { solid } \\
\text { level }(\%)\end{array}$} & \multirow{2}{*}{$\begin{array}{l}\text { Titratable } \\
\text { acidity } \\
\text { levels }{ }^{\mathrm{v}}(\%)\end{array}$} \\
\hline & & $\begin{array}{c}\text { DPPH } \\
(\mathrm{mmol} \mathrm{TE} / 100 \mathrm{~g})\end{array}$ & $\begin{array}{c}\text { FRAP } \\
(\mathrm{mmol} \mathrm{TE} / 100 \mathrm{~g})\end{array}$ & & & & & \\
\hline 1 Northeast & 3 & 2.80 & $5.20 \mathrm{ab}^{\mathrm{u}}$ & 491 & $428 \mathrm{ab}$ & $310 \mathrm{a}$ & 9.4 & $1.10 \mathrm{c}$ \\
\hline 2 Northeast & 2 & 2.92 & $4.55 \mathrm{bc}$ & 444 & $393 \mathrm{ab}$ & $273 \mathrm{a}$ & 7.9 & $1.32 \mathrm{bc}$ \\
\hline 4 Northwest & 3 & 2.93 & $4.82 \mathrm{~b}$ & 441 & $322 \mathrm{abc}$ & $247 \mathrm{a}$ & 8.9 & $1.47 \mathrm{ab}$ \\
\hline 6 South & 3 & 2.90 & $3.31 \mathrm{c}$ & 376 & $177 \mathrm{c}$ & $111 \mathrm{~b}$ & 10.4 & $1.64 \mathrm{a}$ \\
\hline 7 Southwest & 2 & 3.24 & $5.91 \mathrm{a}$ & 526 & $467 \mathrm{a}$ & $320 \mathrm{a}$ & 10.3 & $1.04 \mathrm{c}$ \\
\hline 8 West & 3 & 3.00 & $4.67 \mathrm{bc}$ & 438 & $307 \mathrm{bc}$ & $242 \mathrm{a}$ & 10.0 & $1.34 \mathrm{abc}$ \\
\hline Significance of F $(P)$ & & 0.77 & 0.01 & 0.10 & 0.01 & 0.03 & 0.13 & $<0.01$ \\
\hline
\end{tabular}

${ }^{z}$ Values in table represent location means. The data are expressed on a fresh weight basis.

yProduction sites are designated with identification codes from 1 to 8; production site location designations are based on relative position with respect to the state's centrally located capital, Columbus, $\mathrm{OH}$ (lat. $40^{\circ} 00^{\prime} \mathrm{N}$, long. $82^{\circ} 53^{\prime} \mathrm{W}$ ). Production Sites 3 and 5, supplying samples from a single cultivar, were omitted from the analysis.

${ }^{\mathrm{x}} \mathrm{N}=$ the number of samples (cultivars) from each production site.

${ }^{\text {w DPPH }}$ and FRAP are acronyms for total antioxidant capacity as determined by the ferric reducing ability of plasma and the 2,2-diphenyl-1-picrylhydrazyl procedures, respectively.

vitratable acidity values are expressed as citric acid equivalents.

"Means bearing the same postscript are not significantly different at $P=0.05$ according to Duncan's multiple range test. 


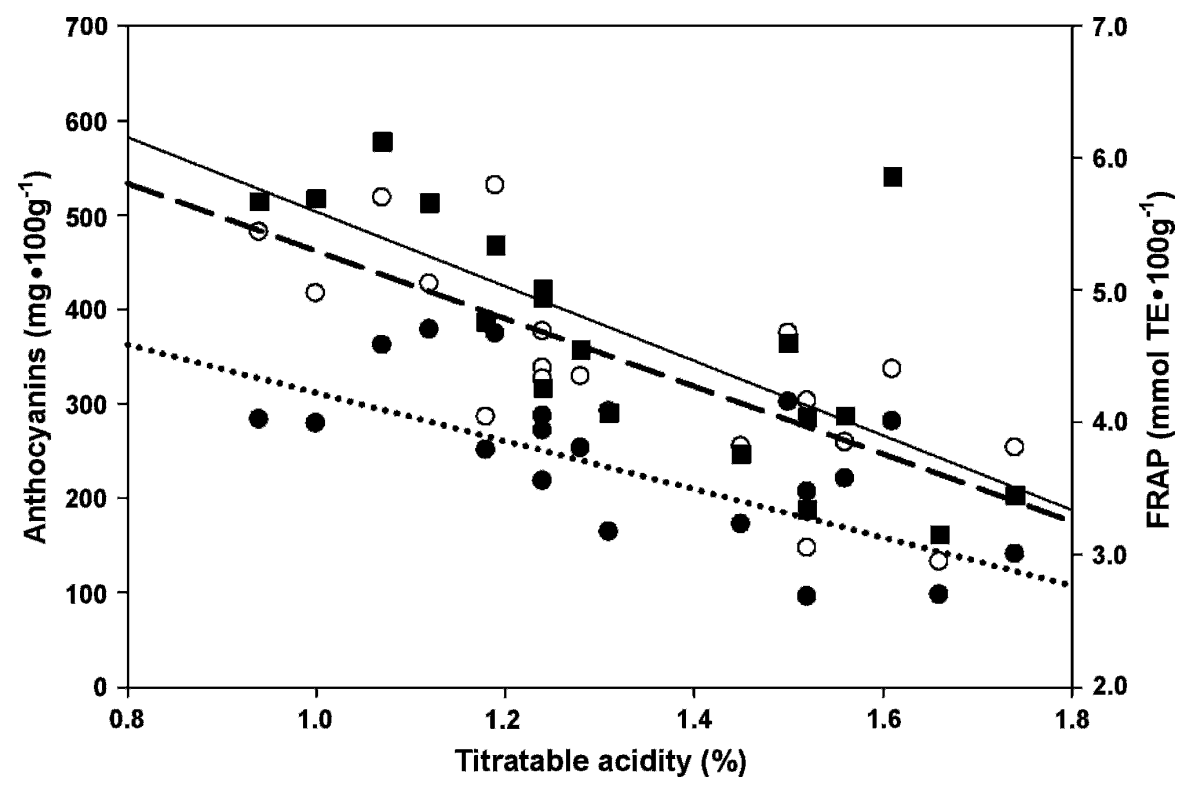

Fig. 3. Relationships between ferric reducing ability of plasma (FRAP), total monomeric anthocyanin and cyanidin 3-rutinoside versus titratable acidity levels during the fruiting period of 19 locally grown black raspberry samples. Markers represent sample mean values. Data are expressed on a fresh weight basis. FRAP values versus titratable acidity $(\mathrm{Y}=-2.8 \mathrm{X}+8.4 ; r=-0.72)$ are represented by closed square markers and a solid regression line. Total monomeric anthocyanin levels versus titratable acidity $(\mathrm{Y}=-347 \mathrm{X}+799 ; r=-0.74)$ are represented by open circles and a dashed regression line. Levels of cyanidin 3-rutinoside versus titratable acidity levels $(\mathrm{Y}=-236 \mathrm{X}+134 ; r=-0.65)$ are represented by closed circles and a dotted regression line.

Table 3. Soil and site characteristics, planting condition, cultural practices, and yield characteristics at eight Ohio production sites supplying 19 black raspberry samples in $2004^{z}$.

\begin{tabular}{|c|c|c|c|c|c|c|}
\hline $\begin{array}{l}\text { Production site } \\
\text { designation and } \\
\text { relative location }\end{array}$ & Soil type & Soil pH & $\begin{array}{l}\text { Age of } \\
\text { planting } \\
\text { (yrs) }\end{array}$ & Bed type & $\begin{array}{l}\text { Canopy } \\
\text { density }^{x}\end{array}$ & $\begin{array}{l}\text { Comparative } \\
\text { yield }^{w}\end{array}$ \\
\hline 1 Northeast & Silt loam & 6.0 to 6.5 & 6 to $8,22^{v}$ & Flush & 5 to 6 & Average \\
\hline 2 Northeast & Silt loam & 6.0 to 6.5 & 3 to 4 & Flush & 7 & Average \\
\hline 3 North & Clay loam & 7.0 & 3 to 5 & Raised & 2 to 3 & Average \\
\hline 4 Northwest & Clay $^{\mathrm{u}}$ & 6.7 to 7.2 & 4 to 5 & Raised & 5 to 8 & Low \\
\hline 5 Northwest & Sandy loam & 7.0 & 2 & Flush & Variable $\mathrm{t}^{\mathrm{t}}$ & Low \\
\hline 6 South & Silt loam & 6.5 to 7.0 & 5 & Raised $^{\mathrm{s}}$ & 4 to 5 & Low \\
\hline 7 Southwest & Silt loam & 6.3 & 9 & Flush & 3 & Average \\
\hline 8 West & $\begin{array}{l}\text { Sandy clay } \\
\text { loam }\end{array}$ & 6.5 to 7.0 & 3 to 4 & Raised & 3 to 4 & Above average \\
\hline
\end{tabular}

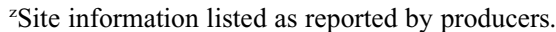

${ }^{\text {y }}$ Production sites (farms) are designated with identification codes from 1 to 8 ; production site location designations are based on relative position with respect to the state's centrally located capital, Columbus, $\mathrm{OH}$ (lat. $40^{\circ} 00^{\prime} \mathrm{N}$, long. $82^{\circ} 53^{\prime} \mathrm{W}$ ).

${ }^{\mathrm{x}}$ Canopy density rating scale: 1 = all berries totally exposed to sunlight; $10=$ very dense foliage with a large portion of the fruit shaded during development.

${ }^{\text {w }}$ Comparison of site yields with the state average as perceived by producers.

'Plantings of 'Jewel' and 'MacBlack' and planting of 'Bristol', respectively.

"A sand ridge is also present in a portion of the field.

tFoliage density and plant vigor exhibit noticeable within-row variability with largest, densest plants near the west end of each row.

${ }^{\mathrm{s}}$ Bed covered with black, tightly woven polypropylene horticultural fabric (5 oz, needle-punched, ultraviolet-stabilized, $98.7 \%$ opaque) for weed control.

antioxidant capacity have been substantiated most clearly in strawberry and grape (e.g., Li et al., 2003; Mori et al., 2007; Spayd et al., 2002; Wang and Zheng, 2001). Light exposure and temperature effects specifically are known to influence the activity of phenolic pathway enzymes (e.g., Boo et al., 2006; Li et al., 2003) and nuclear events, which control their synthesis (e.g., Mori et al., 2007; Takos et al., 2006), especially with respect to accumulation of anthocyanins in fruits.

OARDC Weather System data (OARDC, 2007) collected at the four stations closest to the sites reflected the state's regional climatic differences during the 2004 season, 30 May to 1 Aug. (Fig. 4A-F). Weather parameter weekly averages fluctuated throughout the season, but climatic patterns were similar among regions. Ambient maxima and minima were warmest in the south, although actual temperature differences were not extreme. Over the entire season, ambient temperature differences among regions averaged only 1 to $2{ }^{\circ} \mathrm{C}$. The two western regions were characterized as receiving higher radiation levels and having drier air than the south and northeast. Conversely, the northeast was more humid and more often cloud-covered (data not shown). Soil temperatures measured at a depth of $10 \mathrm{~cm}$ were substantially warmer in the south, by as much as 9 to $10^{\circ} \mathrm{C}$, than those in the two northern regions in a given sampling period. Southwest/western region soil temperatures also exceeded those of the northern regions from late June to late July. These regional soil temperature differences are consistent from year to year (data not shown). Cumulative rainfall was higher in the two northern regions than in the two southern regions, but most significant rain events were outside of the fruiting periods of the samples within each region.

Because fruiting periods for each sample occurred during different portions of the season depending on cultivar and production site, macroclimatic data subsets were created for each sample representing the 7-d period just before harvest initiation (as berries were ripening) and the $10 \mathrm{~d}$ after harvest was initiated (when samples were most likely collected). Cultivars were significantly different $(P=0.025)$ only for ambient maxima with mean day temperatures for the late-ripening 'MacBlack' $\left(28.3{ }^{\circ} \mathrm{C}\right)$ significantly higher than those of the early-ripening 'Bristol' $\left(26.8{ }^{\circ} \mathrm{C}\right)$; the mean ambient maxima among 'Jewel' samples $\left(27.4{ }^{\circ} \mathrm{C}\right)$ was not significantly different from others. Table 4 presents macroclimatic data fruiting period subset means for locations. Only relative humidity and soil temperature means were significantly different among locations and these differences reflected seasonal patterns among regions depicted in Figure 4C and Figure 4E, respectively. Relative humidity levels were not associated with phytonutrient contents. Relationships of FRAP, TMA, and cyanidin 3-rutinoside versus regional differences in soil temperature were significant but relatively weak (Fig. 5), driven primarily by the high soil temperatures in southern Ohio (i.e., values for Site 6). The data arrays presented in Figure 5 suggest that if soil temperatures affect phytonutrient levels, they do so only after a threshold has been reached. Actual soil temperatures at Site 6 may have been elevated further, because it was the only site where within-row horticultural fabric (tightly woven black polypropylene; A.M. Leonard Inc., Piqua, $\mathrm{OH}$ ) covered the root zone (Table 3). The presence of artificial mulch and mulch color had a significant, but variable, effect on phenolic levels and contents of anthocyanins or ellagic acid in strawberries (Anttonen et al., 2006; Wang et al., 1998).

In this study, we surveyed 19 locally grown black raspberry samples representing four cultivars produced in the U.S. midwest for their antioxidant capacity and phytonutrient content. Although the phytonutritional parameters of 'Jewel' have been reported previously, the antioxidant capacities, TP contents, and TMA levels for 'Bristol', 'Haut', and 'MacBlack' likely have been described here for the first time. Our phytonutritional assessments and relationships among antioxidant capacity and phenolic 

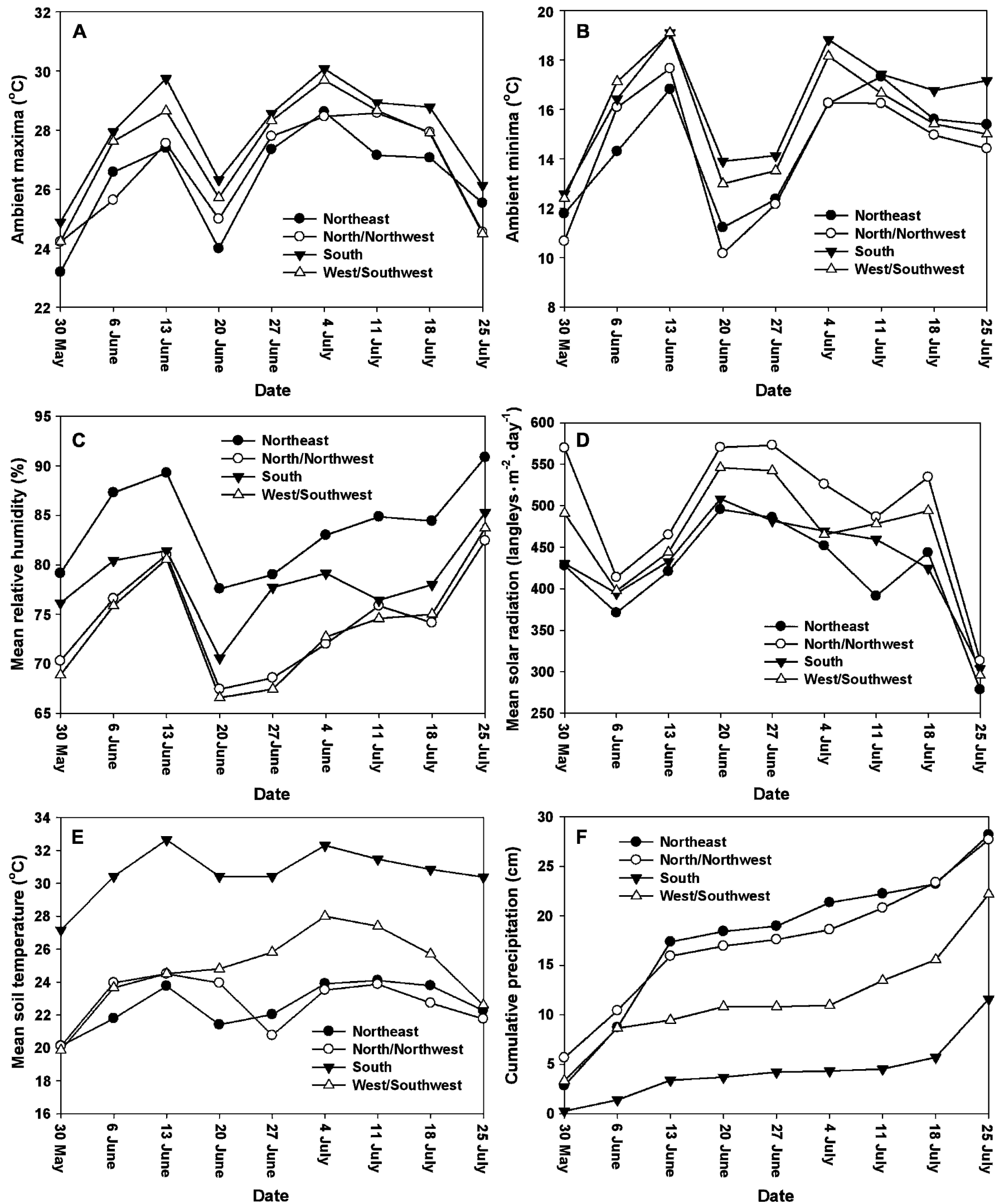

Fig. 4. Regional climatic features estimated from OARDC Weather System data collected at four stations in different regions: the Wooster Station (lat. $40.77^{\circ} \mathrm{N}$, long. $81.93^{\circ} \mathrm{W}$, elevation $311 \mathrm{~m}$ ) representing northeastern Ohio (Sites 1 and 2); the Northwest Station (lat. $41.28^{\circ} \mathrm{N}$, long. $83.84^{\circ} \mathrm{W}$, elevation $693 \mathrm{~m}$ ) representing northern and northwestern Ohio (Sites 3, 4, and 5); the Piketon Station (lat. $39.07^{\circ} \mathrm{N}$, long. $83.01^{\circ} \mathrm{W}$, elevation $578 \mathrm{~m}$ ) representing southern Ohio (Site 6); and the Western Station (lat. 39.83 $\mathrm{N}$, long. 83.63 W, elevation $1124 \mathrm{~m}$ ) representing western and southwestern Ohio (Sites 7 and 8 ). (A) Ambient maxima; (B) ambient minima; (C) mean relative humidity; (D) mean solar radiation; (E) mean soil temperature at a depth of $10 \mathrm{~cm}$. For A-E, graphed values represent the weekly means of daily readings for weeks beginning on dates indicated. (F) Cumulative precipitation. For F, graphed values represent incremental increases in seasonal precipitation through the last day of the week for weeks beginning on dates indicated. 
Table 4. Estimates of ambient temperature, relative humidity, soil temperature, solar radiation, and cumulative precipitation during fruiting periods for 'Bristol', 'Jewel', and 'MacBlack' black raspberries grown at six Ohio production sites ${ }^{\mathrm{z}}$.

\begin{tabular}{|c|c|c|c|c|c|c|c|}
\hline $\begin{array}{l}\text { Production site } \\
\text { designation and } \\
\text { relative location }\end{array}$ & $\mathrm{N}^{\mathrm{x}}$ & $\begin{array}{l}\text { Ambient } \\
\text { maximum } \\
\text { temp }\left({ }^{\circ} \mathrm{C}\right)\end{array}$ & $\begin{array}{l}\text { Ambient } \\
\text { minimum } \\
\text { temp }\left({ }^{\circ} \mathrm{C}\right)\end{array}$ & $\begin{array}{l}\text { Relative } \\
\text { humidity } \\
(\%)\end{array}$ & $\begin{array}{l}\text { Soil } \\
\text { temp } \\
\left({ }^{\circ} \mathrm{C}\right)^{\mathrm{w}}\end{array}$ & $\begin{array}{c}\text { Radiation } \\
\left(\mathrm{L} \cdot \mathrm{m}^{-2} \cdot \mathrm{d}^{-1}\right)^{\mathrm{v}}\end{array}$ & $\begin{array}{l}\text { Cumulative } \\
\text { precipitation } \\
(\mathrm{cm})\end{array}$ \\
\hline 1 Northeast & 3 & 27.5 & 15.0 & $82 \mathrm{a}^{\mathrm{u}}$ & $23.2 \mathrm{c}$ & 450 & 3.9 \\
\hline 2 Northeast & 2 & 27.0 & 14.6 & $82 \mathrm{a}$ & $22.5 \mathrm{c}$ & 461 & 2.6 \\
\hline 4 Northwest & 3 & 27.2 & 14.0 & $72 \mathrm{bc}$ & $23.4 \mathrm{c}$ & 529 & 4.3 \\
\hline 6 South & 3 & 28.1 & 16.2 & $77 \mathrm{ab}$ & $31.0 \mathrm{a}$ & 452 & 2.8 \\
\hline 7 Southwest & 2 & 27.0 & 15.3 & $72 \mathrm{bc}$ & $25.0 \mathrm{~b}$ & 495 & 4.5 \\
\hline 8 West & 3 & 28.0 & 15.3 & $70 \mathrm{c}$ & $26.2 \mathrm{~b}$ & 510 & 1.9 \\
\hline Significance of $\mathrm{F}(P)$ & & 0.71 & 0.66 & $<0.01$ & $<0.01$ & 0.06 & 0.52 \\
\hline
\end{tabular}

zite macroclimatic features were estimated from 2004 OARDC Weather System data (OARDC, 2007) collected at four stations closest to production sites. Climatic data means and sDs were compiled with reference to the fruiting period of each sample (i.e., $7 \mathrm{~d}$ before to $10 \mathrm{~d}$ after typical harvest initiation date) at each site. Values in table represent location means.

yProduction sites are designated with identification codes from 1 to 8; production site location designations are based on relative position with respect to the state's centrally located capital, Columbus, OH (lat. $40^{\circ} \mathrm{N} 00^{\prime} \mathrm{N}$, long. 82 $53^{\prime} \mathrm{W}$ ). Production Sites 3 and 5, supplying samples from a single cultivar, were omitted from the analysis.

${ }^{\mathrm{x}} \mathrm{N}=$ the number of samples (cultivars) from each production site.

${ }^{\text {w }}$ Soil temperatures taken at $10-\mathrm{cm}$ depth.

${ }^{\mathrm{v}} \mathrm{L}=$ langleys.

uMeans bearing the same postscript are not significantly different at $P=0.05$ according to Duncan's multiple range test.

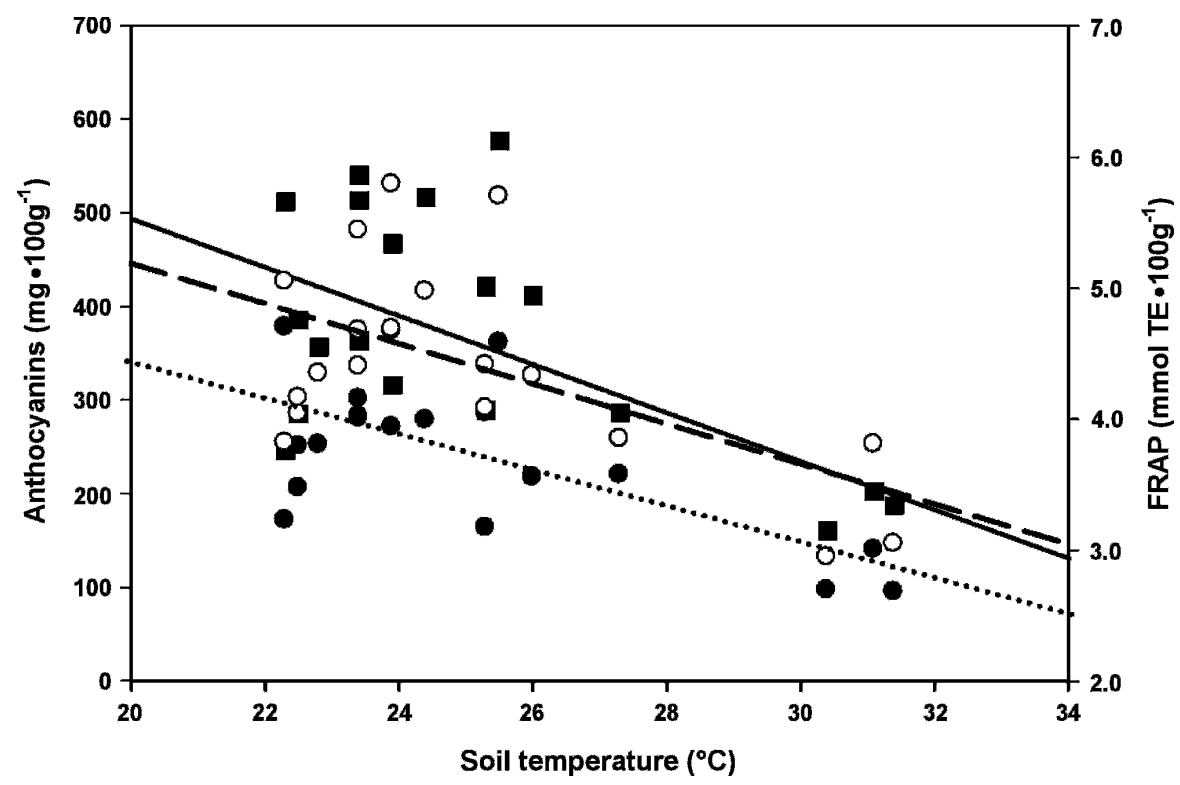

Fig. 5. Relationships between ferric reducing ability of plasma (FRAP), total monomeric anthocyanin, and cyanidin 3-rutinoside versus regional soil temperatures during the fruiting period of 19 locally grown black raspberry samples. Markers represent sample mean values. Data are expressed on a fresh weight basis. FRAP values versus soil temperatures $(\mathrm{Y}=-0.18 \mathrm{X}+9.1 ; r=-0.57)$ are represented by closed square markers and a solid regression line; soil temperatures versus total monomeric anthocyanin levels $(\mathrm{Y}=-21.3 \mathrm{X}+870 ; r=-0.58)$ are represented by open circles and a dashed regression line. Levels of cyanidin 3-rutinoside versus soil temperatures $(\mathrm{Y}=-18.7 \mathrm{X}+714 ; r=-0.66)$ are represented by closed circles and a dotted regression line.

antioxidant levels were generally in agreement with published research based on samples from field studies, genetic investigations, germplasm collections, or from point source surveys.

The importance of cultivar in determining fruit phytonutrient content is well substantiated in the literature. However, our study also illustrated the potential significant influence of environment and cultural practices on antioxidant capacity, TP, and TMA levels of directly marketed midwestern black raspberries. Samples varied most substantially for TMA levels and levels of cyanidin 3-rutino- stantial increases in the anthocyanin content of intact, visually ripe black raspberry fruit as they progressed through the last two stages of ripening [i.e. from berries that could be removed from the torus with modest force to berries that could be removed from the torus easily (data not shown)]. Therefore, differences in harvest practices or harvester skill levels may impact phytonutritional value of black raspberries from different sources. Although the significantly lower levels of FRAP, TMA, and cyanidin 3-rutinoside found in fruit from Site 6 may have been influenced by high soil temperatures, our evidence for these effects are far from definitive. Higher than optimal growing temperatures have been shown to inhibit anthocyanin accumulation in many species, including grape (Mori et al., 2007); apple (Malus $\times$ domestica Borkh.; Kevany et al., 2003); lettuce (Lactuca sativa L.; Gazula et al., 2007); sweetpotato [Ipomeoea batatas (L.) Lam.; Islam et al., 2005); and chicory (Cichorium intybus L.; Boo et al., 2006). However, in the few studies reporting decreased anthocyanin synthesis at high soil temperatures (e.g., Solomakhin and Blanke, 2007), the effect was confounded with those of light intensity or quality.

Site characteristics and cultural practices undoubtedly affect the environmental inputs to and physiological status of small fruits. However, the combination of cultural and environmental factors that resulted in the apparent production site effects exhibited by our samples may be complex and far beyond our ability to explain using data patterns generated in this survey. These production site differences are, however, physiologically significant and warrant future study. Moreover and more importantly, regardless of its environmental or physiological drivers, point-source variation in fruit phytonutrient contents may have substantial impact on overall nutritional benefits to the consumer and affect the quality advantages associated with direct-marketed fruit (Ellerman and McFeeters, 2001). Finally, variability among samples may have important implications in designing reproducible clinical applications, where the efficacy of fruit and fruit products are being tested for their potential benefits against degenerative diseases of aging.

\section{Literature Cited}

Anttonen, M.J., K.I. Hoppula, R. Nestby, M.J. Verheul, and R.O. Karjalainen. 2006. Influence of fertilization, mulch color, early forcing, fruit order, planting date, shading, growing environment and genotype on the contents of selected phenolics in strawberry (Fragaria xananassa Duch.) fruits. J. Agr. Food Chem. 54:2614-2620.

Anttonen, M.J. and R.O. Karjalainen. 2005. Environmental and genetic variation of phenolic compounds in red raspberry. Food Composition and Analysis 18:759-769.

Benvenuti, S., F. Pellati, M. Melegari, and D. Bertelli. 2004. Polyphenols, anthocyanins, ascorbic acid and radical scavenging activity of Rubus, Ribes, and Aronia. J. Food Sci. 69:C164-C169. 
Boo, H.O., S.U. Chon, and S.Y. Lee. 2006. Effects of temperature and plant growth regulators on anthocyanin synthesis and phenylalanine ammonialyase activity in chicory (Cichorium intybus L.). J. Hortic. Sci. Biotechnol. 81:478-482.

Connor, A.M., C.E. Finn, T.K. McGhie, and P.A. Alspach. 2005a. Genetic and environmental variation in antioxidant activity and total phenolic content among blackberry and hybridberry cultivars. J. Amer. Soc. Hort. Sci. 130:527-533.

Connor, A.M., C.E. Finn, T.K. McGhie, and P.A. Alspach. 2005b. Genetic and environmental variation in anthocyanins and their relationship to antioxidant activity in blackberry and hybridberry cultivars. J. Amer. Soc. Hort. Sci. 130:680-687.

Connor, A.M., T.K. McGhie, M.J. Stephens, H.K. Hall, and P.A. Alspach. 2005c. Variation and heritability estimates of anthocyanins and their relationship to antioxidant activity in a red raspberry factorial mating design. J. Amer. Soc. Hort. Sci. 130:534-542.

Connor, A.M., M.J. Stephens, H.K. Hall, and P.A. Alspach. 2005d. Variation and heritabilities of antioxidant activity and total phenolic content estimated from a red raspberry factorial experiment. J. Amer. Soc. Hort. Sci. 130:403-411.

Ellerman, J. and D. McFeeters. 2001. Direct marketing as a value-added opportunity for agriculture. Ohio State Univ. Ext. Factsheet AE8-01. 11 Apr. 2008. <http://ohioline.osu.edu>.

Funt, R.C., M.A. Ellis, R.N. Williams, D.J. Doohan, J.C. Scheerens, and C. Welty. 1999. Brambles - Production management and marketing. Ohio State Univ. Ext. Bull. 782-99. 11 Apr. 2008. <http://ohioline.osu.edu>.

Gazula, A., M.D. Kleinhenz, J.C. Scheerens, and P.P. Ling. 2007. Anthocyanin levels in nine lettuce (Lactuca sativa) cultivars: Influence of planting date and relations among analytic, instrumented and visual assessments of color. HortScience 42:232-238.

Giusti, M.M. and R.E. Wrolstad. 2005. Characterization and measurement of anthocyanins by uv-visible spectroscopy. Unit F1.2, p. 19-31. In: Wrolstad, R.E. and S.J. Schwartz (eds.). Handbook of food analytical chemistry. Wiley, New York, NY.

Han, C.H., H. Ding, B. Casto, G.D. Stoner, and S.M. D'Ambrosio. 2005. Inhibition of the growth of premalignant and malignant human oral cell lines by extracts and components of black raspberries. Nutr. Cancer 51:207-217.

Hecht, S.S., C. Huang, G.D. Stoner, J. Li, P.M.J. Kenney, S.J. Sturla, and S.G. Carmella. 2006. Identification of cyanidin glycosides as constituents of freeze-dried black raspberries which inhibit anti-benzo[a]pyrene-7,8-diol9,10-epoxide induced NFKB and AP-1 activity. Carcinogenesis 27:1617-1626.

Islam, M.S., M. Jalaluddin, J.O. Garner, M. Yoshimoto, and O. Yamakawa. 2005. Artificial shading and temperature influence on anthocyanin compositions in sweetpotato leaves. HortScience 40:176-180.

Kalt, W. 2005. Effects of production and processing factors on major fruit and vegetable antioxidants. J. Food Sci. 70:R11-R19.

Kalt, W., C.F. Forney, A. Martin, and R.L. Prior. 1999. Antioxidant capacity, vitamin C, phenolics and anthocyanins after fresh storage of small fruits. J. Agr. Food Chem. 47:4638-4644.

Kevany, B.M., R. Van Agtmael, D.R. Dilley, and J.B. Golding. 2003. Postharvest temperature affects colour development in 'Rome' apples. Acta Hort. 626:623-625.
Kresty, L.A., W.L. Frankel, C.D. Hammond, M.E. Baird, J.M. Mele, G.D. Stoner, and J.J. Fromkes 2006. Transitioning from preclinical to clinical chemopreventive assessments of lyophilized black raspberries: Interim results show berries modulate markers of oxidative stress in Barrett's esophagus patients. Nutr. Cancer 54:148-156.

Li, Y., H. Yan, B. Zhou, S. Kawabata, and R. Sakiyama. 2003. Role of chalcone synthase and dihydrofalvonol reductase in light dependent accumulation of anthocyanins in 'Toyonoka' strawberry fruits. Acta Hort. 626:361-366.

Maas, J.L., G.J. Galletta, and G.D. Stoner. 1991. Ellagic acid, an anticarcinogen in fruits, especially in strawberries: A review. HortScience 26:10-14.

Mazza, G. and E. Miniati. 1993. Anthocyanins in fruits, vegetables, and grains. CRC Press, Boca Raton, FL.

McGhie, T.K., H.K. Hall, G.D. Ainge, and A.D Mowat. 2002. Breeding Rubus cultivars for high anthocyanin content and high antioxidant capacity. Acta Hort. 585:495-500.

Mori, K., N. Goto-Yamamoto, M. Kitayama, and K. Hashizume. 2007. Loss of anthocyanins in red-wine grape under high temperature. J. Expt. Bot. 58:1935-1945.

Moyer, R.A., K.E. Hummer, C.E. Finn, B. Frei, and R.E. Wrolstad. 2002. Anthocyanins, phenolics, and antioxidant capacity in diverse small fruits: Vaccinium, Rubus, and Ribes.. J. Agr. Food Chem. 50:519-525.

Ohio Agricultural Research and Development Center. 2007. The OARDC Weather System. 11 Apr. 2008. <http:/www.oardc.ohio-state.edu/ newweather $>$.

Ozgen, M., A.Z. Tulio, Jr., A.M. Chanon, N. Janakiraman, R.N. Reese, A.R. Miller, and J.C. Scheerens. 2006a. Phytonutrient accumulation and antioxidant capacity at eight developmental stages of black raspberry fruit. HortScience 41:1082. (abstr.).

Ozgen, M., A.Z. Tulio, Jr., R.N. Reese, J.C. Scheerens, and A.R. Miller. 2006b. Modified 2,2-azino-bis-3-ethylbenzothiazoline-6-sulfonic acid method to measure antioxidant capacity of selected small fruits and comparison to ferric reducing antioxidant power and 2,2,-diphenyl-1picrylhydrazyl methods. J. Agr. Food Chem. 54:1151-1157.

Perkins-Veazie, P.M., J.K. Collins, and J.R. Clark. 1996. Cultivar and maturity affect postharvest quality of fruit from erect blackberries. HortScience 31:258-261.

Seeram, N.P., L.S. Adams, Y. Zhang, R. Lee, D. Sand, H.S. Scheuller, and D. Heber. 2006. Blackberry, black raspberry, blueberry, cranberry, red raspberry and strawberry extracts inhibit growth and stimulate apoptosis of human cancer cells in vitro. J. Agr. Food Chem. 54:9329-9339.

Singleton, V.L., R. Orthofer, and R.M. LamuelaRaventós. 1999. Analysis of total phenols and other oxidation substrates and antioxidants by means of Folin-Ciocalteu reagent. Methods Enzymol. 299:152-178.

Singleton, V.L. and J.L. Rossi. 1965. Colorimetry of total phenolics with phosphomolybdicphosphotungstic acid reagents. Amer. J. Enol. Viticult. 16:144-158.

Solomakhin, A.A. and M.M. Blanke. 2007. Overcoming adverse effects of hailnets on fruit quality and microclimate in an apple orchard. J. Sci. Food Agr. 87:2625-2637.

Spayd, S.E., J.M. Tarara, D.L. Mee, and J.C Ferguson. 2002. Separation of sunlight and temperature effects on the composition of Vitis vinifera cv. Merlot berries. Amer. J. Enol. Viticult. 53:171-182.
Stoner, G.D., C. Sardo, G. Apseloff, D. Mullet, W Wargo, V. Pound, A. Singh, J. Sanders, R. Aziz, B. Casto, and X.L. Sunday. 2005. Pharmacokinetics of anthocyanins and ellagic acid in healthy volunteers fed freeze-dried black raspberries daily for 7 days. J. Clin. Pharmacol. 45:1153-1164.

Stoner, G.D., L.S. Wang, N. Zikri, T. Chen, S.S. Hecht, C. Huang, C. Sardo, and J.F. Lechner. 2007. Cancer prevention with freeze-dried berries and berry components. Semin. Cancer Biol. 17:403-410.

Takos, A.M., F.W. Jaffe, S.R. Jacob, J. Bogs, S.P. Robinson, and A.R. Walker. 2006. Lightinduced expression of a $M Y B$ gene regulates anthocyanin biosynthesis in red apples. Plant Physiol. 142:1216-1232.

Tian, Q., R.M. Aziz, G.D. Stoner, and S.J. Schwartz. 2005. Anthocyanin determination in black raspberry (Rubus occidentalis) and biological specimens using liquid chromatographyelectrospray ionization tandem mass spectrometry. J. Food Sci. 70:C43-C47.

Tian, Q., M.M. Giusti, G.D. Stoner, and S.J. Schwartz. 2006. Urinary excretion of black raspberry (Rubus occidentalis) anthocyanins and their metabolites. J. Agr. Food Chem. 54: 1467-1472.

Tulio A.Z., Jr., R.N. Reese, F.J. Wyzgoski, P.L. Rinaldi, R. Fu, J.C. Scheerens, and A.R. Miller. 2008. Cyanidin 3-rutinoside and cyanidin 3xylosylrutinoside as primary phenolic antioxidants in black raspberry. J. Agr. Food Chem. $56: 1880-1888$.

U.S. Department of Health and Human Services, U.S. Department of Agriculture. 2005. Dietary guidelines. 11 Apr. 2008. <http://www. healthierus.gov/dietaryguidelines>

Wang, S.I., G.J. Galletta, M.J. Camp, and M.J. Kasperbauer. 1998. Mulch type affects fruit quality and composition of two strawberry genotypes. HortScience 33:636-640.

Wang, S.I. and H.S. Lin. 2000. Antioxidant activity in fruits and leaves of blackberry, raspberry and strawberry varies with cultivar and developmental stage. J. Agr. Food Chem. 48:140146.

Wang, S.I. and W. Zheng. 2001. Effect of plant growth temperature on antioxidant capacity in strawberry. J. Agr. Food Chem. 49:4977-4982.

Wang, S.I. and W. Zheng. 2005. Preharvest application of methyl jasmonate increases fruit quality and antioxidant capacity in raspberries. Int. J. Food Sci. Technol. 40:187-195.

Weber, C.A. 2003. Genetic diversity in black raspberry detected by RAPD markers. HortScience 38:269-272.

World Health Organization. 2003. Diet, nutrition and the prevention of chronic diseases. WHO Technical Report Series. No. 916 (TRS 916). 11 Apr. 2008. <http://www.who.int/dietphysicalactivity/ publications/trs916/download/en/index.html>.

Wu, X., G.R. Beecher, J.M. Holden, D.B. Haytowitz, S.E. Gebhardt, and R.L. Prior. 2004. Lipophilic and hydrophilic antioxidant capacities of common foods in the United States. J. Agr. Food Chem. 52:4026-4037.

Xue, H., R.M. Aziz, N. Sun, J.M. Cassady, L.M. Kamendulis, Y. Xu, G.D. Stoner, and J.E. Klaunig. 2001. Inhibition of cellular transformation by berry extracts. Carcinogenesis 22:351-356.

Zafrilla, P., F. Ferreres, and F.A. Tomás-Barberán 2001. Effect of processing and storage on the antioxidant ellagic acid derivatives and flavonoids of red raspberry (Rubus idaeus) jams. J. Agr. Food Chem. 49:3651-3655. 